\title{
Effective Communication in the Pre-Operative Environment
}

\author{
Lauren Van Decar*, Zacherie Conover, Lopa Misra \\ Department of Anesthesiology and Peri-Operative Medicine, Mayo Clinic, Phoenix, AZ, USA \\ Email: ^Vandecar.Lauren@mayo.edu, Conover.Zacherie@mayo.edu,Misra.Lopa@mayo.edu
}

How to cite this paper: Van Decar, L., Conover, Z. and Misra, L. (2020) Effective Communication in the Pre-Operative Environment. International Journal of Otolaryngology and Head \& Neck Surgery, 9, $1-7$.

https://doi.org/10.4236/ijohns.2020.91001

Received: November 1, 2019

Accepted: November 26, 2019

Published: November 29, 2019

Copyright $\odot 2020$ by author(s) and Scientific Research Publishing Inc. This work is licensed under the Creative Commons Attribution International License (CC BY 4.0).

http://creativecommons.org/licenses/by/4.0/ (c) (i) Open Access

\begin{abstract}
Introduction: Building a strong patient rapport is a founding principle instilled early on in medical education. For many specialties, this relationship can be developed through repeated encounters. However, anesthesiologists are limited in opportunity for which such rapport can be built. Therefore, it is critical that the pre-operative visit is used effectively to develop a strong patient-physician relationship and help relieve patient anxiety. Methods: The primary objective of this study was to determine what communication aspects are most important to patients in the pre-operative period. Secondary objectives were to evaluate the effectiveness of our current communication practices and their impact on patient's anxiety. This study was an anonymous and voluntary survey conducted in the pre-operative area prior to elective surgical cases at Mayo Clinic Arizona from Dec. 2018-Jan. 2019. Patients completed a one-page questionnaire ranking the importance of various communication aspects and its subsequent impact on their anxiety level. Results: Of the communication qualities evaluated, patients most valued their physician's thoroughness and ability to describe their anesthetic plan. Greater than $95 \%$ of patients felt "very satisfied" with their anesthesia provider encounter and on a 1 - 5 point scale, with 5 being the highest, there was an average reduction of 0.75 in anxiety level after completion of the anesthesia interview. Conclusion: Incorporation of and improving these communication aspects during your pre-operative evaluation can help improve rapport, reduce patient anxiety, and improve the patient's overall experience. Implementing a communication-focused curriculum during training may prove beneficial in improving resident's effectiveness in communicating.
\end{abstract}

\section{Keywords}

Communication, Pre-Operative, Anesthesia, Patient Anxiety 


\section{Introduction}

Building a strong patient rapport is a founding principle instilled early on in medical education and has been shown to improve patient outcomes [1]. Studies have shown that physicians may only have seconds in which to build connection and trust with their patients. For many specialties, this relationship can be molded and grown over months to years of repeated encounters. However, many anesthesiologists are limited in time and commonly have only a single visit for which such rapport can be built. Therefore, it is critical that the pre-operative visit is used effectively to develop and enhance the patient-physician relationship and help relieve patient anxiety.

This survey was designed to help develop an understanding of what patients perceive as important aspects of the anesthesia interview on the day of surgery. Typically, this brief patient encounter is focused on information gathering, patient education, consent, and patient-provider relationship formation. Occasionally, patients are referred to the Pre-Operative Evaluation clinic where they see a medical provider, who is not always an anesthesiologist, to medically optimize their comorbidities. Given the brevity of the pre-operative anesthesia interview, a provider has one encounter with limited time to establish a strong rapport. Better understanding of how to quickly accomplish this whilst meeting the other goals of the pre-operative evaluation is important to the successful practice of anesthesia and has not been previously evaluated. Additionally, the anesthesia training process, specifically for residents, may not always focus on communicating with patients as part of the curriculum.

The primary objective of this study was to determine what communication aspects are most valued to patients in the pre-operative period. Secondary objectives were to evaluate the effectiveness of our current communication practices with patients, our impact on their pre-operative anxiety, and comparison of anesthesia residents' and staff anesthesiologists' communication scores.

\section{Materials and Methods}

Prior to the implementation of our survey, we submitted our proposal to the Mayo Clinic Internal Institutional Review Board. Upon approval of the project by the IRB as Quality Improvement, a one-page survey was created to assess a variety of characteristics of the interviewer/examiner, as well as to rank the degree of importance of several descriptors and attributes of their provider. Reference Figure 1 for example of survey distributed to patients. The criteria evaluated from this survey was selected based on previous studies demonstrating the value of such similar attributes in patient communication in other settings [2] [3].

Inclusion criteria included all elective inpatient and outpatient surgical patients older than 18 years of age that were engaged by an anesthesiologist and/or anesthesia resident at the Mayo Clinical Arizona Surgical Services from Dec. 2018-Jan. 2019. Exclusion criteria included non-English speaking patients, patient refusal, inability to comprehend and complete the survey, inadequate time 


\section{Patient Preanesthesia Evaluation Questionnaire}

A voluntary and anonymous survey

Were you seen by an anesthesiologist, anesthesia resident, or both before surgery? PLEASE CIRCLEONE

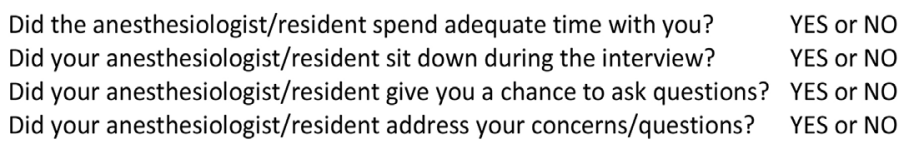

Rank in order of importance:1 being least important \& 5 being most important, use each number once Time Spent

Sitting Down

Opportunity to ask questions

Thorough

Eye contact

Please rate your anesthesiologist's/resident's Professionalism:

Very Unprofessional 12345 Very Professional

Please rate your anesthesiologist's/resident's Empathy/Compassion:

Not Empathetic $\quad 12345$ Very Empathetic

Please rate your level of satisfaction with your anesthesiologist's/resident's explanation of the plan:

Very Unsatisfied $\quad 12345$ Very Satisfied

Rank in order of importance:1 being least important \& 5 being most important, use each number once

Professionalism

Explanation of anesthesia -

Knowledge of your history -

Friendliness

What was your level of anxiety before and after your discussion with your anesthesia provider/resident?

$\begin{array}{llllllll}\text { Before: } & \text { Not anxious } & 1 & 2 & 3 & 4 & 5 & \text { Very Anxious } \\ \text { After: } & \text { Not anxious } & 1 & 2 & 3 & 4 & 5 & \text { Very Anxious }\end{array}$

Comments:

What made your anesthesiologist a successful communicator?

What made your anesthesiologist less effective as a communicator?

Figure 1. Single page survey distributed to patients.

for survey completion, and urgent or emergent cases.

Once the patient was roomed in the pre-operative area, the anesthesia provider conducted their typical preoperative assessment without an observer. Thereafter, prior to embarking to the operating room, the patient completed the survey in a voluntary and anonymous manner. Surveys were then collected by the pre-operative nurse and placed in a HIPAA compliant bin. Surveys were collected by a research member and data was entered into HIPPA-compliant REDCap software. We determined that approximately 100 - 150 surveys would be sufficient to provide us with adequate data for evaluation. It was estimated that a response rate of $20 \%-30 \%$ could be expected, and as such we planned on distributing 300 surveys. 


\section{Results}

Approximately 300 surveys were distributed to patients and 130 anonymously completed surveys were collected (a response rate of $43.3 \%$ ) and data was entered into the REDCap software system. Surveys which were collected that included missing data/answers or numerical ranking which were incomplete or uninterpretable for a portion of the answers were excluded from the analysis for that specific question.

Subjects were asked to identify which type of anesthesia provider evaluated them. $11(8.7 \%)$ chose anesthesiologist, none $(0.0 \%)$ chose anesthesia resident, 6 $(4.7 \%)$ identified that they were seen by both, 110 (86.6\%) did not know, and 3 did not respond to this question. The practice at our institution requires patients to be seen, evaluated and consented by a staff anesthesiologist, meaning $100 \%$ of the patients communicated with an anesthesiologist on the day of surgery. $\mathrm{Pa}$ tients are commonly evaluated a second time by an anesthesia resident just prior to proceeding to the OR.

The results from single answer questions regarding characteristics and communication skills of their provider were overwhelmingly positive. When asked if the provider spent adequate time with them, gave them a chance to ask questions, and addressed their concerns/questions. 129 responders (100\%) answered yes to these three questions. $61(47.3 \%)$ respondents reported that their provider sat down, while 67 (51.9\%) said they did not sit down (1 responded that they did not know and 1 did not answer that question).

The subsequent series of questions asked the responders to rank several general characteristics of the pre-operative evaluation in order of importance (time spent, sitting down during the interview, allowing for the opportunity to ask questions, thoroughness, and making eye contact). The results of the section of the survey are shown in Table 1 with thoroughness being ranked as most important.

Table 1. Ranking of importance of general characteristics.

\begin{tabular}{|c|c|c|c|c|c|c|}
\hline Characteristic & 1 & 2 & 3 & 4 & 5 & $\begin{array}{c}\text { Average } \\
\text { Rank }\end{array}$ \\
\hline Time Spent & $\begin{array}{c}8 \\
(6.3 \%)\end{array}$ & $\begin{array}{c}20 \\
(15.9 \%)\end{array}$ & $\begin{array}{c}26 \\
(20.6 \%)\end{array}$ & $\begin{array}{c}29 \\
(23.0 \%)\end{array}$ & $\begin{array}{c}43 \\
(34.1 \%)\end{array}$ & 3.63 \\
\hline Sitting Down & $\begin{array}{c}78 \\
(62.4 \%)\end{array}$ & $\begin{array}{c}9 \\
(7.2 \%)\end{array}$ & $\begin{array}{c}6 \\
(4.8 \%)\end{array}$ & $\begin{array}{c}9 \\
(7.2 \%)\end{array}$ & $\begin{array}{c}23 \\
(18.4 \%)\end{array}$ & 2.12 \\
\hline $\begin{array}{l}\text { Opportunity to } \\
\text { Ask Questions }\end{array}$ & $\begin{array}{c}4 \\
(3.1 \%)\end{array}$ & $\begin{array}{c}10 \\
(7.9 \%)\end{array}$ & $\begin{array}{c}16 \\
(12.6 \%)\end{array}$ & $\begin{array}{c}38 \\
(29.9 \%)\end{array}$ & $\begin{array}{c}59 \\
(46.5 \%)\end{array}$ & 4.09 \\
\hline Thoroughness & $\begin{array}{c}3 \\
(2.3 \%)\end{array}$ & $\begin{array}{c}7 \\
(5.5 \%)\end{array}$ & $\begin{array}{c}9 \\
(7.0 \%)\end{array}$ & $\begin{array}{c}16 \\
(12.5 \%)\end{array}$ & $\begin{array}{c}93 \\
(72.7 \%)\end{array}$ & 4.48 \\
\hline Eye Contact & $\begin{array}{c}5 \\
(3.9 \%)\end{array}$ & $\begin{array}{c}30 \\
(23.4 \%)\end{array}$ & $\begin{array}{c}28 \\
(21.9 \%)\end{array}$ & $\begin{array}{c}16 \\
(12.5 \%)\end{array}$ & $\begin{array}{c}49 \\
(38.3 \%)\end{array}$ & 3.58 \\
\hline
\end{tabular}

Note: $\operatorname{Rank}(1=$ least important to patient, $5=$ most important to patient $)$. 
Survey responders were then asked to rate several attributes of their actual anesthesia provider (professionalism, empathy/compassion, and explanation of the anesthesia plan). The responses for these were largely positive with 5 out of 5 scores as follows: Professionalism 96.9\%, Empathy/Compassion 92.2\%, and ability to explain anesthesia plan $95.3 \%$.

The subjects' responses to the second ranking question on the survey required the ranking of attributes based on importance to the subject, depicted in Table 2. Ranked attributes included professionalism, ability to explain the anesthesia plan, knowledge of patient history, and friendliness. Of these, the ability to explain the anesthesia plan was ranked as most important.

For the assessment of the provider's ability to affect the subject's level of anxiety, they were asked to rate their level of anxiety before and after their preoperative anesthesia evaluation on a 1 - 5 scale, 5 being the highest level of anxiety. While the overall levels of anxiety varied widely, the average reduction in anxiety was 0.748 (points on $1-5$ scale) and was statistically significant $(\mathrm{P}<0.0001)$.

\section{Discussion}

The ability to focus on the specific aspects of the pre-operative anesthesia interview which patients find most valuable may allow providers to establish rapport and patient trust more quickly and reliably. The ranking of communication characteristics in this survey analysis reveals that the ability to clearly explain the anesthesia plan to the patient as well as overall thoroughness is viewed as most important. Interestingly, making eye contact, sitting down, and friendliness were considered less important compared to other aspect of the interview. Clearly explaining the anesthesia plan has previously been show to important in to patients and improves anxiety [4]. While displaying confident and approachable body language is no doubt important, there are likely other areas which may be more important to focus on, especially for trainees who are trying to improve their interview and communication skills [2] [3].

Overall the survey responses regarding the communication performance of the anesthesia providers showed that patients were overwhelming satisfied with

Table 2. Ranking of provider attributes.

\begin{tabular}{ccccccc}
\hline Attributes & $\mathbf{1}$ & $\mathbf{2}$ & $\mathbf{3}$ & $\mathbf{4}$ & $\mathbf{5}$ & $\begin{array}{c}\text { Average } \\
\text { Rank }\end{array}$ \\
\hline Professionalism & 5 & 16 & 29 & 18 & 58 & 3.86 \\
& $(4.0 \%)$ & $(12.7 \%)$ & $(23.0 \%)$ & $(14.3 \%)$ & $(46.0 \%)$ & \\
$\begin{array}{c}\text { Ability to explain } \\
\text { anesthesia plan }\end{array}$ & 12 & 3 & 12 & 29 & 70 & 4.13 \\
Knowledge of & 4 & $(2.4 \%)$ & $(9.5 \%)$ & $(23.0 \%)$ & $(55.6 \%)$ & \\
patient history & $(3.2 \%)$ & $(10.4 \%)$ & $(17.6 \%)$ & $(27.2 \%)$ & $(41.6 \%)$ & 3.94 \\
Friendliness & 5 & 45 & 17 & 15 & 42 & \\
& $(4.0 \%)$ & $(36.3 \%)$ & $(13.7 \%)$ & $(12.1 \%)$ & $(33.9 \%)$ & 3.35 \\
\hline
\end{tabular}

Note: $\operatorname{Rank}(1=$ least important to patient, $5=$ most important to patient). 
their interactions. This may hint toward a responder bias though all participants were ensured of anonymity. Perhaps the timing of the survey being after the preoperative interview but before anesthesia might have caused this effect. As a result, we placed more importance on the ranking sections of the survey. Additionally, we found that overall our patients had an improvement in the levels of preoperative anxiety by nearly 1 point on average (on a 1 to 5 scale) after their encounter with the anesthesia provider.

Identifying oneself and explaining the extent of involvement with a patients' care is important in establishing a good patient-provider relationship. Transparency on the part of trainees may also be an important part of the informed consent process. This survey found that at our institution, role identification may be an area of improvement, as $86.6 \%$ of responders were not able to distinguish whether they were seen by a resident, an anesthesiologist, or both.

A key component of anesthesia education is learning to complete efficient yet thorough pre-operative interviews and examinations that yield useful medical information but also establish trust from their patients. This can be especially challenging in the early stages of training when there may be more emphasis on information gathering and interpretation then on rapport building, which has been shown to increase patient satisfaction [5]. We feel that implementation of a structured curriculum focusing on preoperative interview skill development through observation as well as simulation may be invaluable to resident education.

A limitation of this study is the timing for which surveys could be completed by the patients. Based on the practice at our institution, anesthesia residents commonly are limited on time to see the patient in between cases and commonly conduct their interview just prior to proceeding to the operating room. Thus, limiting the patient's ability to conduct a survey based on their communication with the resident and limited our ability to compare residents to staff anesthesiologists' communication scores. A second limitation was this survey was conducted at a single institution with possible limited sociodemographics and age which may limit its generalizability to all patient populations.

\section{Conclusion}

Emphasis on thoroughness and description of the anesthetic plan during your pre-operative evaluation can potentially help improve rapport, reduce patient anxiety, and improve the patient's overall experience. Implementing a simulation or observation-based communication curriculum during residency may prove beneficial in improving resident's effectiveness in communicating with peri-operative patients.

\section{Acknowledgements}

Marlene E Girado, MS, Health Sciences Research, Division of Biostatistics, Mayo Clinic Arizona. 


\section{Conflicts of Interest}

The authors declare no conflicts of interest regarding the publication of this paper.

\section{Disclosure Statement}

No competing financial interests exist.

\section{References}

[1] Stewart, M. (1995) Effective Physician-Patient Communication and Health Outcomes: A Review. Canadian Medical Association Journal, 152, 1423-1433.

[2] Swayden, K.J., Anderson, K.K., Connelly, L.M., et al. (2012) Effect of Sitting vs. Standing on Perception of Provider Time at Bedside: A Pilot Study. Patient Education and Counseling, 86, 166-171. https://doi.org/10.1016/j.pec.2011.05.024

[3] Forkin, K.T., Dun, L.K., et al. (2019) Influence of Sex and Body Language on Patient Perceptions of Anesthesiologists. Anesthesiology, 130, 314-321. https://doi.org/10.1097/ALN.0000000000002527

[4] Bondy, L.A., Sims, N., Schroeder, D.R., et al. (1999) The Effect of Anesthetic Patient Education on Preoperative Patient. Regional Anesthesia and Pain Medicine, 24, 158-164.

[5] Harms, C., Young, J.R., Amsler, F., Zettler, C., Scheidegger, D. and Kindler, C.H. (2004) Improving Anaesthetists' Communication Skills. Anaesthesia, 59, 166-172. https://doi.org/10.1111/j.1365-2044.2004.03528.x 